\title{
Establishment and Application of a Method for the Determination of Ganoderic Acid $A$
}

\author{
Shengyun Li (D), Yaowu Yuan (D), Chenchen Yu $(D)$, Hao Gao $(D)$, Jianxin Tan (D), \\ and Yiling Tian $(\mathbb{D})$ \\ College of Food Science and Technology, Hebei Agricultural University, No. 289 Lingyusi Street, Baoding 071001, Hebei, China \\ Correspondence should be addressed to Yiling Tian; ty-69@163.com
}

Received 15 October 2020; Revised 11 November 2020; Accepted 20 November 2020; Published 30 November 2020

Academic Editor: Fatma M. El-Demerdash

Copyright ( $\odot 2020$ Shengyun Li et al. This is an open access article distributed under the Creative Commons Attribution License, which permits unrestricted use, distribution, and reproduction in any medium, provided the original work is properly cited.

\begin{abstract}
A method for the quantitative determination of ganoderic acid A was constructed using the principle of indirect competitive enzyme-linked immunosorbent assay (ELISA), and this method was used to determine the ganoderic A contents of Ganoderma lucidum samples in the market. The conjugate of ganoderic acid $A$ and bovine serum albumin was used for four rounds of immunization on test rabbits to obtain rabbit antiganoderic acid $A$ antibody IgG. The enzyme-labeled plate was coated with the conjugate of ganoderic acid $A$ and ovalbumin. The first stage reaction in the indirect competitive ELISA was that the conjugate of ganoderic acid $A$ in the sample competed with the conjugate coated on the enzyme-labeled plate to bind rabbit antibodies. The second stage reaction was the combination of goat anti-rabbit IgG-horseradish peroxidase and rabbit antiganoderic acid $A$ antibody IgG. The results of the determination of ganoderic acid $A$ standard by this method showed that the coefficient of variation of repeated wells in the group was $<5 \%$, the detection limit of ganoderic acid A was $0.6 \mu \mathrm{g} / \mathrm{L}$, and ganoderic acid A had a substantial dose-response relationship in the content range of $0.9-72.9 \mu \mathrm{g} / \mathrm{L}\left(R^{2}=0.994\right)$. This method was used to measure the ganoderic $A$ content of 12 varieties of G. lucidum in the market and showed the obvious differences in the ganoderic acid $A$ contents of the different varieties. This method is simple, fast, and of great importance to the quality control of Ganoderma products.
\end{abstract}

\section{Introduction}

Ganoderma is rich in a variety of active ingredients, and its pharmacological effects are different. Triterpene is one of the main active components of Ganoderma lucidum. Triterpene has liver-protective [1], antitumor [2, 3], immunitystrengthening $[4,5]$, and antioxidation functions $[6,7]$, and it lowers blood lipid and blood sugar $[8,9]$. According to investigation and analysis, the triterpenoid contents of different types of G. lucidum vary greatly, and the triterpenoid contents between wild and cultivated G. lucidum differ greatly [10-12]. Ganoderic acid A accounts for the largest proportion of G. lucidum triterpenes and is one of the Ganoderma triterpenoid markers [13]. Ganoderic acid A plays a major role in improving immunity [14]. Therefore, the development of a fast and simple method with a low detection limit for the determination of ganoderic acid A is of great importance for the quality control of Ganoderma products. At present, the detection methods of ganoderic acid A include visible light colorimetry [15], UV spectrophotometry $[16,17]$, high-performance liquid chromatography [18-21], and chromatography-mass spectrometry $[22,23]$. The main drawbacks of these methods are the high cost of the highly specialized instrument, difficulty in popularizing the method, and long detection time. Therefore, providing a simple and rapid detection method of ganoderic acid $A$ is an urgent problem that needs to be solved. The purpose of this research was to use the principle of enzyme-linked immunosorbent assay (ELISA) to construct a method for the quantitative determination of ganoderic acid $A$ and determine and analyze the ganoderic acid $A$ contents of different G. lucidum varieties in the market. ELISA includes antigen coating, sample loading reaction, and substrate color development. The method used in this experiment was indirect competitive ELISA. The sample loading reaction involved two stages. The first stage is 
the competition between the ganoderic acid A in the sample and the conjugate coated on the enzyme-labeled plate to bind rabbit antiganoderic acid $A$ antibody IgG, and the second stage is the combination of goat anti-rabbit IgGhorseradish peroxidase (HRP) and rabbit antiganoderic acid $A$ antibody IgG.

\section{Materials and Methods}

2.1. Materials. Chicken egg albumin and albumin bovine $V$ from Sigma; ganoderic acid $A$, soy saponin $\mathrm{Ab}$, and saikosaponin $D$ from Shanghai Yuanye Bio-Technology Co., Ltd.; ginsenoside Rb1, betulinic acid, and jujuboside $B$ from Chengdu Sikehua Biotechnology Co., Ltd.; lucidenic acid $A$ and ganoderic acid $Y$ from Shanghai Yuduo Biotechnology Co., Ltd.; ganoderic acid $B$ from Shanghai Tauto Biotechnology Co., Ltd.; glycyrrhizic acid and notoginsenoside R1 from Macklin; Anemarrhena saponin from Zzstandard; aescin from Aladdin; and ELISA plate from JET Biofil were used in this study. G. lucidum, Ganoderma leucocontextum, Ganoderma atrum, Ganoderma applanatum, Trametes orientalis, Fomitopsis pinicola, Fuscoporia punctata, Piptoporus betulinus, Fomes fomentarius, Coriolus versicolor, Inonotus cuticularis, and Fomitopsis rosea were sourced from various provinces and cities in China.

\subsection{Methods}

2.2.1. Preparation of the Conjugate of Ganoderic Acid A and Bovine Serum Albumin. Bovine serum albumin (500 mg) was dissolved in $8 \mathrm{~mL}$ of $2 \%$ sodium bicarbonate-tetrahydrofuran (THF) solution (1:1). Ganoderic acid $A$ (100 mg), 1-hydroxybenzotriazole $\quad(140 \mathrm{mg}), \quad \mathrm{N}, \mathrm{N}$-diisopropylcarbodiimide $\left(140 \mathrm{mg}\right.$ ), and $1 \mathrm{~mL}$ of THF were stirred at $0-5^{\circ} \mathrm{C}$ for $1 \mathrm{~h}$ to form an activated ester. The $20 \%$ of the total mass of the activated ester solution was added to the bovine serum albumin solution and reacted at room temperature for $2-4 \mathrm{~h}$. The solution was freeze-dried for $48 \mathrm{~h}$ to obtain a powder. The powder was dissolved in $50 \mathrm{~mL}$ of purified water and filtered with a $0.45 \mu \mathrm{m}$ filter membrane to remove insoluble materials. The filtrate was collected and permeated with a permeable membrane with a molecular weight cutoff of $3 \mathrm{kD}$ for $10 \mathrm{~h}$. The purified water was changed every $2 \mathrm{~h}$. The solution was freeze-dried for $72 \mathrm{~h}$ after permeation treatment to obtain a solid powder, which is the conjugate of ganoderic acid $A$ and bovine serum albumin.

2.2.2. Preparation of the Conjugate of Ganoderic Acid A and Chicken Egg Albumin. Bovine serum albumin was replaced with chicken egg albumin in 2.2.1.

2.2.3. Preparation of Rabbit Antiganoderic Acid A Immune Serum and Purification of Antibody IgG. Two healthy Japanese white rabbits were selected, and the conjugate of ganoderic acid $\mathrm{A}$ and bovine serum albumin was used as the immunogen. Four rounds of immunization were carried out, and the dose of the conjugate was $1 \mathrm{mg}$ per round for each rabbit. The first round of vaccination conjugate was mixed with Freund's incomplete adjuvant. A subcutaneous multipoint injection was used. The second, third, and fourth rounds of immunization were performed after 14 days. The latter three rounds of inoculation did not need an adjuvant and were injected by ear vein at an interval of 7 days. At 7 days after the fourth round of vaccination, the antiganoderic acid $A$ immune serum was separated by cardiac blood sampling, Purified to IgG, by A protein affinity chromatography column, and concentrated to original volume $4^{\circ} \mathrm{C}$ save.

2.2.4. Determination of the Effect of Ganoderic Acid A Antibody. The titer of rabbit antiganoderic acid A antibody IgG was determined by indirect competitive ELISA. The conjugate of ganoderic acid $\mathrm{A}$ and bovine serum albumin was dissolved in carbonate buffer at pH 9.6 and coated on an enzyme-labeled plate at a concentration of $20 \mu \mathrm{g} / \mathrm{mL}$. After standing for $24 \mathrm{~h}$ at $4^{\circ} \mathrm{C}$, the coating buffer was discarded and washed with a phosphate-buffered solution with Tween (PBST) three times. The rabbit antiganoderic acid $A$ antibody IgG solution $(100 \mu \mathrm{L})$ diluted 1:5 times with the sample diluent was added in the small holes in rows 1 and 2, and the rabbit antiganoderic acid $A$ antibody IgG solution $(100 \mu \mathrm{L})$ absorbed by bovine serum albumin and diluted $1: 5$ times with the sample diluent was added to the small holes in rows 3 and 4 (treatment method: 10\% bovine serum albumin solution was prepared with sample diluent, $4 \mathrm{~mL}$ of the bovine serum albumin solution was added to $1 \mathrm{~mL}$ of rabbit antiganoderic acid A antibody IgG solution, and let stand at $4^{\circ} \mathrm{C}$ for $48 \mathrm{~h}$ so that the treated solution was equivalent to the original antibody solution diluted by $1: 5$ times). In the last column of the four rows of holes, $100 \mu \mathrm{L}$ of negative serum with $1: 100$ dilution was added as the control. The solution was shaken in a microplate constant temperature shaker at $200 \mathrm{r} / \mathrm{min}$ for $30 \mathrm{~min}$ at $37^{\circ} \mathrm{C}$. After $30 \mathrm{~min}$, the reaction solution was discarded and washed with PBST three times. The HRP-IgG solution (100 $\mu \mathrm{L})$ diluted with $1: 1000$ sample diluent was added to the holes and shaken in the microplate constant temperature shaker at $200 \mathrm{r} / \mathrm{min}$ for $30 \mathrm{~min}$ at $37^{\circ} \mathrm{C}$. After $30 \mathrm{~min}$, the reaction solution was discarded and washed with PBST three times. TMB substrates $A$ and $B$ were mixed as the substrate working solution. The substrate working solution $(100 \mu \mathrm{L})$ was added to each well and shaken in the microplate constant temperature shaker at $200 \mathrm{r} / \mathrm{min}$ for $15 \mathrm{~min}$ at $37^{\circ} \mathrm{C}$. Then, $50 \mu \mathrm{L}$ of stop solution was added to each well. After $3 \mathrm{~min}$, a microplate reader was used to measure the absorbance of each test well at a wavelength of $450 \mathrm{~nm}$.

2.2.5. Selection and Verification of the Coating Antigen. Indirect competitive ELISA was used to verify the effectiveness of the five coating antigens that competed with ganoderic acid $A$. Ganoderic acid $A$, the conjugate of ganoderic acid $A$ and chicken egg albumin, the conjugate of ganoderic acid $\mathrm{A}$ and bovine serum albumin, chicken egg albumin, and bovine serum albumin were selected as the coating antigens. Each antigen was applied on one row of holes on the enzyme-labeled plate. The coating and washing process is as described in 2.2.4. Ganoderic acid $A$ standard 
product was diluted with sample diluent to a concentration of $1 \mu \mathrm{g} / \mathrm{mL}$. Then, $50 \mu \mathrm{L}$ of this product was added to columns $A-D$ in each row, and $50 \mu \mathrm{L}$ of sample diluent was added to columns $E-H$ as the control. The rabbit antiganoderic acid $A$ antibody $\operatorname{IgG}$ solution $(50 \mu \mathrm{L})$ diluted with sample diluent to $1: 200$ was added to each row and placed in the microplate thermostatic oscillator at $200 \mathrm{r} / \mathrm{min}$ for $30 \mathrm{~min}$ at $37^{\circ} \mathrm{C}$, and the subsequent steps were as described in 2.2.4.

2.2.6. Establishment of Indirect Competitive ELISA for Ganoderic Acid A and Formulation of Regression Curve. The process of coating the ELISA plate and coating and washing the conjugate of ganoderic acid $A$ and chicken egg albumin are as described in 2.2.4. Ganoderic acid $A$ standard was dissolved with sample diluent and divided into 10 dose groups $(0,0.1,0.3,0.9,2.7,8.1,24.3,72.9$, 218.7 , and $656.3 \mu \mathrm{g} / \mathrm{L})$. Ganoderic acid $A$ standard solution $(50 \mu \mathrm{L})$ was added to the corresponding wells of the enzyme-labeled plate, and three wells were used for each concentration. The rabbit antiganoderic acid A antibody IgG solution $(50 \mu \mathrm{L})$ diluted with sample diluent $1: 200$ was added to each well and placed in the microplate thermostatic oscillator at $200 \mathrm{r} / \mathrm{min}$ for $30 \mathrm{~min}$ at $37^{\circ} \mathrm{C}$, and the subsequent steps followed that in 2.2.4. The coefficient of variation $(\mathrm{C} \cdot \mathrm{V})$ of the absorbance values of repeated wells in the group was calculated using the formula: $\mathrm{C} \cdot \mathrm{V}=($ standard deviation/average value $) \times$ $100 \%$. The relative absorbance value of each dose group was calculated as follows: relative absorbance value $=A$ / $A_{0} \times 100 \%$, where $A$ represents the average absorbance value of a certain concentration of ganoderic acid $A$ reaction well, and $A_{0}$ represents the average absorbance value of the $0 \mu \mathrm{g} / \mathrm{L}$ ganoderic acid A reaction well. The relative absorbance value of each dose group of ganoderic acid A was analyzed by ANOVA to compare the significance of the differences between the groups. The regression curve and regression equation of the relationship between the relative absorbance value and the concentration of ganoderic acid A were obtained by curve fitting.

2.2.7. Verification of the Specificity of Ganoderic Acid A by Indirect Competitive ELISA. Twelve test substances of the same triterpenoids as ganoderic acid $A$, namely, ganoderic acid $B$, ganoderic acid $Y$, lucidenic acid $A$, ginsenoside $\mathrm{Rb} 1$, betulinic acid, jujuboside $B$, soy saponin $A b$, glycyrrhizic acid, saikosaponin $D$, Anemarrhena saponin, aescin, and notoginsenoside R1, were selected. After proper dilution, the determination was conducted according to the method in 2.2.6. If the test substance had certain cross-reactivity and a dose-response relationship existed, the regression curve and regression equation of the relationship between the relative absorbance value and content of each test substance were prepared. According to the regression equation, the $50 \%$ inhibition concentration of the test substance (50\% inhibition concentration is the sample concentration that corresponds to $50 \%$ of the relative absorbance value on the regression curve) was calculated, and the cross-reaction rate with ganoderic acid $A$ was calculated by the formula: cross-reaction rate $=(50 \%$ inhibitory concentration of ganoderic acid $A / 50 \%$ inhibitory concentration of the tested substance) $\times 100 \%$. If the tested substance had no obvious cross-reactivity and cannot reach the $50 \%$ inhibition rate at the maximum detection concentration, the cross-reaction rate was estimated to be less than a certain value according to the calculation formula.

\subsubsection{G. lucidum Sample Processing Method and Determi-} nation of Ganoderic Acid A Recovery Rate. Dried G. lucidum was pulverized and passed through a 20 -mesh sieve. A $2.5 \mathrm{~g}$ sample was placed in a $100 \mathrm{~mL}$ flask with a stopper, added with $25 \mathrm{~mL}$ of absolute ethanol, stoppered and shaken for $1 \mathrm{~min}$, soaked for $24 \mathrm{~h}$, then stoppered and shaken for $1 \mathrm{~min}$, and filtered with filter paper. An appropriate amount of sample solution was collected, gradually diluted five times with the sample diluent, and subjected to an indirect competitive ELISA method as established in 2.2.6. Ganoderic acid $A$ standard was determined to draw the regression curve. According to the relative absorbance value of the sample, the content of ganoderic acid $A$ that corresponded to the sample solution was checked on the standard curve. The ganoderic acid $A$ content of the dried G. lucidum was expressed by $X$ in microgram per kilogram according to formula (1). After obtaining the ganoderic acid $A$ content of the dried G. lucidum, standard ganoderic acid $A$ was added at $0.5,1.0,1.5$, and 2 times the content to the G. lucidum samples and then determined using the same method. The recovery rate of the sample addition was obtained according to the formula: recovery rate of sample addition $=($ measured value of spiked sample - measured value of sample)/spiked amount $\times 100 \%$.

$$
X=\frac{\rho \times V \times n}{m},
$$

where $\rho$ is the content of ganoderic acid $A$ in the sample extract found from the standard curve, in microgram per liter; $V$ is the volume of sample extraction solution, in liter; $N$ is the dilution factor of the sample; $M$ is the mass of the sample, in kilograms.

\subsubsection{Determination of Ganoderic Acid A in Different Kinds} of G. lucidum Dry Products. Twenty-four dried G. lucidum products, including twelve G. lucidum, four G. leucocontextum, four G. atrum, and four G. applanatum, were selected from different sources in Ganodermataceae. Twenty-four dried G. lucidum analogues from different sources that are commonly called G. lucidum and belong to Polyporaceae in taxonomy were selected. Three samples of each of the following analogues were used: T. orientalis, F. pinicola, F. punctata, $P$. betulinus, F. fomentarius, C. versicolor, I. cuticularis, and F. rosea. The samples were treated according to the method in 2.2.8. The indirect competitive ELISA established in 2.2.6 was 
TABLE 1: Determination results of antibody solution at different dilutions.

\begin{tabular}{lccccccc}
\hline Antibody dilution factor & $1: 25$ & $1: 125$ & $1: 625$ & $1: 3125$ & $1: 15625$ & $1: 78125$ & $1: 390625$ \\
\hline Treated group & + & + & + & + & - & - & - \\
Untreated group & + & + & + & + & + & + & + \\
\hline
\end{tabular}

“+" means positive result; “-” means negative.

TABLE 2: Test results of five kinds of coating antigens.

\begin{tabular}{|c|c|c|c|c|c|}
\hline Item & Ganoderic acid $A$ & $\begin{array}{c}\text { Conjugate of } \\
\text { ganoderic acid } A \\
\text { and } \\
\text { chicken egg albumin }\end{array}$ & $\begin{array}{l}\text { Conjugate of ganoderic } \\
\text { acid } A \text { and } \\
\text { bovine serum albumin }\end{array}$ & $\begin{array}{l}\text { Chicken egg } \\
\text { albumin }\end{array}$ & $\begin{array}{l}\text { Bovine serum } \\
\text { albumin }\end{array}$ \\
\hline $\begin{array}{l}\text { Average absorbance value of the } \\
\text { competitive group }\end{array}$ & 0.067 & 0.187 & 2.018 & 0.112 & 2.032 \\
\hline $\begin{array}{l}\text { Average absorbance value of the } \\
\text { control group }\end{array}$ & 0.076 & 1.796 & 2.022 & 0.119 & 2.018 \\
\hline Competitiveness presentation rate (\%) & $11.8 \%$ & $89.6 \%$ & $0.2 \%$ & $5.9 \%$ & $-0.7 \%$ \\
\hline
\end{tabular}

used to determine their ganoderic acid $A$ contents, which were later analyzed by single-factor ANOVA.

\section{Results and Analysis}

3.1. Results and Analysis of Ganoderic Acid A Antibody Titer Determination. The average absorbance value of the repeat wells was calculated after indirect competitive ELISA. The result was considered positive if the average absorbance value of the test group or the average luminosity value of the negative control group $\geq 2.1$. The judgment results under each dilution multiple of the treatment group and untreated group are shown in Table 1 . In this test, the maximum dilution factor at which a positive result appears was determined as the efficacy value of the test antibody. From Table 1, the efficacy value of the antibody in the group after the absorption of bovine serum albumin was $1: 3125$, and the efficacy value of the antibody in the group that had not been absorbed by bovine serum albumin was $1: 78125$. The results showed that the inoculation of the conjugate of ganoderic acid $\mathrm{A}$ and bovine serum albumin produced a considerable amount of antibody IgG in the test rabbits, of which a large amount of antibody IgG bound to bovine serum albumin, and only a small part of antibody IgG bound to ganoderic acid $A$.

3.2. Results and Analysis of the Choice of Coating Antigen. After the absorbance values of the five coating antigens were measured by indirect competitive ELISA, the competitiveness presentation rate of each coating antigen was calculated according to the formula: competitiveness presentation rate $=($ the average absorbance value of the control group- the average absorbance value of the competition group)/ the average absorbance value of the control group $\times 100 \%$. The effectiveness of the coating antigen was analyzed by the competitiveness presentation rate. The results are shown in Table 2. Only the conjugate of ganoderic acid A and chicken egg albumin achieved a high presentation rate. The reasons for the lower rate of the other coating antigens are different:

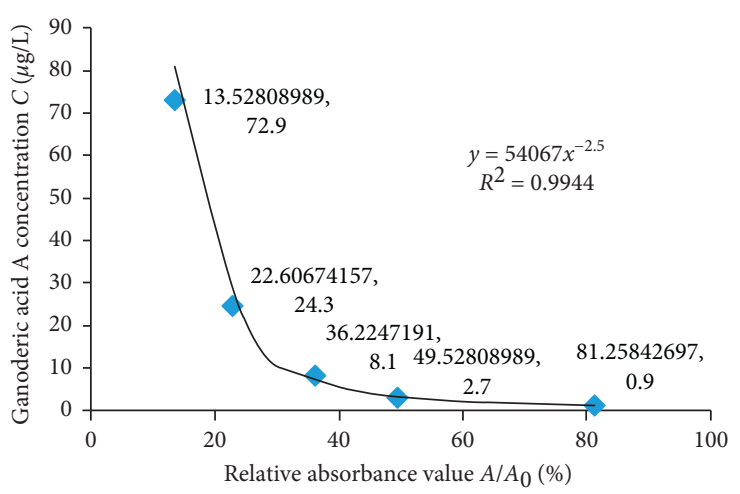

FIGURE 1: Regression curve of the relationship between relative absorbance and ganoderic acid $A$ concentration.

The reason for the low presentation rate of Ganoderma acid A coating is that it can not bind to the enzyme label effectively; the reason for the low presentation rate of chicken egg white albumin coating is that the anti-Ganoderma acid A antibody can not bind to it; the reason for the low presentation rate of bovine serum albumin, Ganoderma acid A, and bovine serum albumin is that a large number of antibovine serum albumin antibodies interfere with the action of Ganoderma acid A antibody in the reaction, which further verifies the analysis in 3.1, that the antibody obtained in Step 2.2.3 contains a large amount of IgG bound to bovine serum albumin. The experiment at this stage confirmed the feasibility of the conjugate of ganoderic acid A and chicken egg albumin as a coating antigen. The conjugate of ganoderic acid $A$ and chicken egg albumin can effectively interact with the rabbit antiganoderic acid A IgG in 2.2.3 without binding to other nonspecific IgGs.

3.3. Establishment of Indirect Competitive ELISA for Ganoderic Acid A and Formulation of Regression Curve. The results of the indirect competitive ELISA of the 10 dose groups of ganoderic acid A showed that the absorbance value showed a gradual decline as the concentration of 
TABLE 3: Results of the cross-reaction between test substance and ganoderic acid $A$.

\begin{tabular}{lccc}
\hline Test material & Cross-reaction rate (\%) & Test material & Cross-reaction rate (\%) \\
\hline Ganoderic acid $B$ & 0.082 & Soybean saponin Ab & $<0.03$ \\
Ganoderic acid $Y$ & $<0.03$ & Glycyrrhizic acid & $<0.03$ \\
Lucidenic acid $A$ & $<0.03$ & Saikosaponin $D$ & $<0.03$ \\
Ginsenoside Rb1 & $<0.03$ & Anemarrhena saponin & $<0.03$ \\
Betulinic acid & $<0.03$ & Aescin & $<0.03$ \\
Jujuboside B & $<0.03$ & Notoginsenoside R1 & $<0.03$ \\
\hline
\end{tabular}

TABLE 4: Determination results of sample processing recovery rate.

\begin{tabular}{|c|c|c|c|c|}
\hline \multicolumn{5}{|c|}{ Determination results of sample processing recovery rate } \\
\hline Additive dosage $(\mu \mathrm{g} / \mathrm{kg})$ & $0.14 \times 10^{6}$ & $0.28 \times 10^{6}$ & $0.42 \times 10^{6}$ & $0.56 \times 10^{6}$ \\
\hline Dose of the spiked sample $(\mu \mathrm{g} / \mathrm{kg})$ & $0.42 \times 10^{6}$ & $0.53 \times 10^{6}$ & $0.67 \times 10^{6}$ & $0.82 \times 10^{6}$ \\
\hline Dose of the nonspiked sample $(\mu \mathrm{g} / \mathrm{kg})$ & $0.27 \times 10^{6}$ & $0.27 \times 10^{6}$ & $0.27 \times 10^{6}$ & $0.27 \times 10^{6}$ \\
\hline Recovery rate $(\%)$ & 107 & 92.9 & 95.2 & 98.2 \\
\hline
\end{tabular}

ganoderic acid $A$ increased. The $\mathrm{C} \cdot \mathrm{V}$ of the absorbance value of repeated wells in each group was calculated as $<5 \%$. One-way ANOVA was performed on the absorbance value of each dose group. The results showed substantial differences in the absorbance values between the adjacent dose groups $0.3,0.9,2.7,8.1,24.3,72.9$, and $218.7 \mu \mathrm{g} / \mathrm{L}$, whereas the differences in the absorbance values between the dose groups $0,0.1$, and $0.3 \mu \mathrm{g} / \mathrm{L}$ and between the dose groups 218.7 and $656.1 \mu \mathrm{g} / \mathrm{L}$ were unremarkable. Further refinement of the group found that the absorbance of ganoderic acid $\mathrm{A}$ at the concentration of $0.6 \mathrm{~g} / \mathrm{L}$ was significantly different from that of $0 \mathrm{~g} / \mathrm{L}$, and the absorbance of Ganoderic acid A at the concentration of $121.5 \mathrm{~g} / \mathrm{L}$ was significantly different from that of $656.1 \mathrm{~g} / \mathrm{L}$. Thus, the data of dose groups $0.9,2.7,8.1,24.3$, and $72.9 \mu \mathrm{g} / \mathrm{L}$ were used for curve fitting. The regression curve of the relationship between the relative absorbance value and the concentration of ganoderic acid A was prepared by taking the relative absorbance value as the abscissa and the concentration of ganoderic acid $A$ as the ordinate. The results are shown in Figure 1. Figure 1 shows that the concentration of ganoderic acid $A$ and relative absorbance had the best correlation degree under the power function relationship, and the value of $R^{2}$ reached 0.994 .

3.4. Results and Analysis of the Specificity of Indirect ELISA for Ganoderic Acid A. The results of the cross-reaction of ganoderic acid A with the 12 kinds of triterpenoid test substances are shown in Table 3. Among them, only ganoderic acid $B$ showed certain cross-reactivity and doseresponse relationship, but the cross-reaction rate with ganoderic acid $A$ was still less than $0.1 \%$. Based on the solubility of the test substance in the sample reaction solution, the maximum reaction concentration of the other 11 test substances was $10 \mathrm{mg} / \mathrm{L}$, which still did not reach the $50 \%$ inhibition rate. Under the same conditions, the 50\% inhibitory concentration of ganoderic acid $A$ was $3.058 \mu \mathrm{g} / \mathrm{L}$; thus, the estimated cross-reaction rate of these test substances was less than $0.03 \%$. Specificity analysis showed that the method has good specificity for the determination of ganoderic acid $A$.

3.5. Results and Analysis of Ganoderic Acid A Recovery Rate in Ganoderma Samples. The ganoderic acid A content of dried G. lucidum was $0.28 \times 10^{6} \mu \mathrm{g} / \mathrm{kg}$, and the corresponding doses of $0.5,1.0,1.5$, and 2 times of its content were $0.14 \times 10^{6}, 0.28 \times 10^{6}, 0.42 \times 10^{6}$, and $0.56 \times 10^{6} \mu \mathrm{g} /$ $\mathrm{kg}$, respectively. The corresponding doses of ganoderic acid $A$ standard was added to the filtered G. lucidum sample, and the determination results are shown in Table 4 . Table 4 shows that the range of standard added recovery was $98.3 \% \pm 6.2 \%$, which indicates that the sample processing method had a high recovery effect and can be applied in the determination of samples.

3.6. Determination and Analysis of Ganoderic Acid $A$ in Different Kinds of G. lucidum. Table 5 shows the determination results of the content of ganoderic acid $\mathrm{A}$ in the dried G. lucidum from the family Ganodermataceae. The table shows that the contents of ganoderic acid $A$ in the four kinds of $G$. lucidum were very different. Single-factor ANOVA showed that the content of ganoderic acid $A$ in G. lucidum was significantly different from the other three types $(P<0.001)$; the ganoderic acid $A$ content of $G$. applanatum was significantly different from that of $G$. leucocontextum and $G$. atrum $(0.01<P<0.05)$; the ganoderic acid A content of $G$. atrum was not significantly different from that of G. leucocontextum $(P>0.05)$. Table 6 shows the determination results of the ganoderic acid A contents of dried G. lucidum analogues to the family Polyporaceae. These dried analogues, which are commonly called G. lucidum, contained a large amount of ganoderic acid $\mathrm{A}$, which even exceeded those in G. leucocontextum and G. atrum. A comparison of the results in Tables 6 and 5 showed that G. lucidum had the highest ganoderic acid $A$ content among all the tested samples. According to one-way ANOVA, the results were significantly different from other varieties $(P<0.01)$. 
TABle 5: Determination results of ganoderic acid A content in G. lucidum from different varieties and sources.

\begin{tabular}{|c|c|c|c|c|c|}
\hline Variety & $\begin{array}{c}\text { Place of } \\
\text { production }\end{array}$ & Concentration $(\mathrm{g} / \mathrm{kg})$ & Variety & $\begin{array}{l}\text { Place of } \\
\text { production }\end{array}$ & Concentration $(\mathrm{mg} / \mathrm{kg})$ \\
\hline \multirow{12}{*}{$\begin{array}{l}\text { Ganoderma } \\
\text { lucidum }\end{array}$} & Jilin & $3.26 \pm 0.13$ & \multirow{4}{*}{$\begin{array}{c}\text { Ganoderma } \\
\text { leucocontextum }\end{array}$} & Sichuan & $2.81 \pm 0.11$ \\
\hline & Hubei & $6.51 \pm 0.32$ & & Yunnan & $2.42 \pm 0.12$ \\
\hline & Yunnan & $3.39 \pm 0.16$ & & Tibet & $4.36 \pm 0.26$ \\
\hline & Shaanxi & $2.27 \pm 0.09$ & & Guizhou & $2.90 \pm 0.08$ \\
\hline & Sichuan & $2.35 \pm 0.11$ & \multirow{4}{*}{ Ganoderma applanatum } & Jilin & $6.68 \times 10 \pm 3.34$ \\
\hline & Anhui & $4.73 \pm 0.23$ & & Yunnan & $3.46 \times 10 \pm 1.38$ \\
\hline & Fujian & $2.98 \pm 0.12$ & & Henan & $3.87 \times 10 \pm 2.32$ \\
\hline & Guangxi & $2.14 \pm 0.1$ & & Sichuan & $1.21 \times 102 \pm 6.06$ \\
\hline & Jiangsu & $1.67 \pm 0.08$ & \multirow{4}{*}{ Ganoderma atrum } & Jilin & $8.09 \pm 0.32$ \\
\hline & Zhejiang & $2.12 \pm 0.1$ & & Yunnan & $5.87 \pm 0.21$ \\
\hline & Hunan & $3.66 \pm 0.18$ & & Guizhou & $5.12 \pm 0.25$ \\
\hline & Guangdong & $2.56 \pm 0.13$ & & Guangxi & $1.04 \pm 0.05$ \\
\hline
\end{tabular}

TABLE 6: Determination results of ganoderic acid A content in dried G. lucidum analogues from different varieties and sources.

\begin{tabular}{lccccc}
\hline Variety & Place of production & Concentration $(\mathrm{mg} / \mathrm{kg})$ & Variety & \multicolumn{2}{c}{ Place of production Concentration $(\mathrm{mg} / \mathrm{kg})$} \\
\hline \multirow{3}{*}{ Trametes orientalis } & Jilin & $8.98 \times 10 \pm 4.48$ & & Jilin & $6.96 \pm 0.28$ \\
& Tibet & $6.74 \times 10 \pm 2.70$ & Fomes fomentarius & Shaanxi & $4.12 \pm 0.17$ \\
& Guizhou & $6.21 \times 10 \pm 2.63$ & & Guangxi & $5.42 \pm 0.25$ \\
\hline \multirow{3}{*}{ Fomitopsis pinicola } & Jilin & $5.45 \times 10 \pm 2.77$ & & Jilin & $7.53 \times 10 \pm 3.56$ \\
& Guangxi & $7.25 \times 10 \pm 3.42$ & Coriolus versicolor & Guangxi & $6.01 \times 10 \pm 2.94$ \\
& Sichuan & $4.56 \times 10 \pm 1.82$ & & Guizhou & $4.05 \times 10 \pm 2.04$ \\
\hline \multirow{3}{*}{ Fuscoporia punctata } & Jilin & $1.07 \times 10 \pm 0.31$ & & Jilin & $3.83 \times 10 \pm 1.61$ \\
& Hubei & $2.16 \times 10 \pm 1.02$ & Inonotus cuticularis & Sichuan & $2.47 \times 10 \pm 0.97$ \\
& Hunan & $2.47 \times 10 \pm 1.01$ & & Hunan & $6.06 \times 10 \pm 2.91$ \\
\hline \multirow{3}{*}{ Piptoporus betulinus } & Jilin & $1.80 \pm 0.07$ & & Jilin & $1.49 \times 10 \pm 0.56$ \\
& Sichuan & $2.84 \pm 0.12$ & Fomitopsis rosea & Sichuan & $1.08 \times 10 \pm 0.53$ \\
& Gansu & $1.06 \pm 0.05$ & & Yunnan & $3.21 \times 10 \pm 1.21$ \\
\hline
\end{tabular}

\section{Conclusions}

This study used synthetic immunogen to obtain antiganoderic acid $\mathrm{A}$ antibodies in the immune serum of experimental rabbits. An indirect competitive ELISA with good specificity and sensitivity for the detection of ganoderic acid A was constructed using synthetic coating antigen and antiganoderic acid A antibody, compared with the high-performance liquid chromatography adopted by Hongling Dong, Duanping Lu, and others $[24,25]$, compared with the liquid chromatography-tandem mass spectrometry adopted by Liangqin Liu and Yongli Liu [26, 27], and compared with the enzyme-linked immunosorbent assay method constructed by Sakamoto Seiichi, Gorawit Yusakul, and others [28-30]. In comparison, this method has a lower detection limit. The established detection method was used to determine the ganoderic acid $A$ contents of $G$. lucidum samples. The results showed that ganoderic acid $A$ contents of different varieties were substantially different, and the content of ganoderic acid $A$ was the highest in G. lucidum. The method is simple and fast for the determination of ganoderic acid A and is of great importance for the quality control of Ganoderma products.

\section{Data Availability}

All data generated or used during the study are included in the submitted article.

\section{Conflicts of Interest}

The authors declare that they have no conflicts of interest.

\section{Authors' Contributions}

The first two authors contributed equally to this manuscript.

\section{Acknowledgments}

This study was financially supported by National Key Research and Development Program of China (Project No. 2018YFD0400200).

\section{References}

[1] R. Chen, "Review of research on chemical constituents of Ganoderma lucidum and its quality control method," Edible and Medicinal Mushrooms, vol. 23, no. 05, pp. 270-275, 2015.

[2] G. Du, H. Wang, Z. Yan et al., "Anti-tumor target prediction and activity verification of Ganoderma lucidum triterpenoids," China Journal of Chinese Materia Medica, vol. 42, no. 03, pp. 517-522, 2017.

[3] Z. H. Lin Zhi-bin, "Anti-tumor and immunoregulatory activities of Ganoderma lucidum and its possible mechanisms," Acta Pharmacologica Sinica, vol. 25, no. 11, pp. 1387-1395, 2004. 
[4] Z.-B. Lin, "Cellular and molecular mechanisms of immunomodulation by ganoderma lucidum," Journal of Pharmacological Sciences, vol. 99, no. 2, pp. 144-153, 2005.

[5] N. Sato, Q. Zhang, C.-M. Ma, and M. Hattori, "Anti-human immunodeficiency virus-1 protease activity of new lanostanetype triterpenoids from ganoderma sinense," Chemical \& Pharmaceutical Bulletin, vol. 57, no. 10, pp. 1076-1080, 2009.

[6] Y. Dong, T. Gao, W. Pan et al., "Optimization of Glycyrrhiza uralensis solid fermented Ganoderma lucidum using response surface methodology and assessment of their antioxidant activity in vitro," Food Science and Technology, vol. 41, no. 01, pp. 7-14, 2016.

[7] G. Yen and J. Wu, "Antioxidant and radical scavenging properties of extracts from Ganoderma tsugae," Food Chemistry, vol. 65, no. 3, pp. 375-379, 1999.

[8] G.-Q. Liu, H.-X. Xiao, X.-L. Wang, Y. Zhao, Y.-G. Zhang, and G.-P. Ren, "Stimulated production of triterpenoids of ganoderma lucidum by an ether extract from the medicinal insect, catharsius molossus, and identification of the Key stimulating active components," Applied Biochemistry and Biotechnology, vol. 165, no. 1, pp. 87-97, 2011.

[9] H. W. Kim and B. K. Kim, "Biomedicinal triterpenoids of ganoderma lucidum (curt.: Fr.) P. Karst. (Aphyllophoro mycetideae)," International Journal of Medicinal Mushrooms, vol. 1, no. 2, pp. 121-138, 1999.

[10] G. Meng, B. Cheng, L. Ye et al., "Active components in wild and cultivated ganoderma fruiting bodies," Fujian Journal of Agricultural Sciences, vol. 33, no. 05, pp. 485-490, 2018.

[11] F. W. R. C. Lin Ma, "Analysis of triterpene constituents from Ganoderma lucidum," Acta Pharmaceutica Sinica, vol. 1, pp. 50-52, 2003.

[12] Z. Xing, Q. Yu, J. Zhang et al., "Comparative study on triterpenes in different ganoderma species," Journal of Chinese Medicinal Materials, vol. 8, pp. 575-576, 2004.

[13] J. Meng, S.-z. Wang, J.-z. He et al., "Ganoderic acid A is the effective ingredient of Ganoderma triterpenes in retarding renal cyst development in polycystic kidney disease," Acta Pharmacologica Sinica, vol. 41, no. 6, pp. 782-790, 2020.

[14] W.-L. Guo, J.-B. Guo, B.-Y. Liu et al., "Ganoderic acid A from Ganoderma lucidum ameliorates lipid metabolism and alters gut microbiota composition in hyperlipidemic mice fed a high-fat diet," Food \& Function, vol. 11, no. 8, pp. 6818-6833, 2020 .

[15] S. Liu, J. Dai, W. Zhang et al., "Comparative analysis of ganoderic acid in ganoderma lucidum mycelium and fruit body with the ultraviolet absorption method and colorimetric method using different standards," Chinese Agricultural Science Bulletin, vol. 31, no. 35, pp. 104-109, 2015.

[16] W. He, L. Ye, and J. Hua, "Quantification of ganoderic acids in ganoderma lucidum and TiaoZhiling by ultraviolet spectrometry," Pharmaceutical Journal of Chinese People's Liberation Army, vol. 01, pp. 74-76, 2006.

[17] W. Li, Z. Wang, Z. Xu et al., "Determination of total triterpenoids in ganoderma lucidum spore oil by spectrophotometry," Food Research and Development, vol. 49, no. 17, pp. 165-170, 2019.

[18] C. Hui, W. Fangsheng, W. Lifeng et al., "Method for determination of content of biological activities constituents ganoderic acid in ganoderma lucidum," Chinese Journal of Veterinary Science, vol. 04, pp. 381-383, 2001.

[19] M. Ramakrishna, D. R. Babu, S. S. Veena, M. Pandey, and N. Rao, "A validated reverse-phase HPLC method for quantitative determination of ganoderic acids $\mathrm{A}$ and $\mathrm{B}$ in cultivated strains of ganoderma spp. (agaricomycetes) indigenous to India," International Journal of Medicinal Mushrooms, vol. 19, no. 5, pp. 457-465, 2017.

[20] H. Wenkang, H. Qinwei, G. Zengxi et al., "Determination on ganoderic acid $\mathrm{A}$ in ganoderma lucidum with different growth stages and different parts by HPLC," Edible Fungi of China, vol. 36, no. 01, pp. 56-58, 2017.

[21] W. Liu, J. Zhang, W. Han et al., "One single standard substance for the simultaneous determination of 17 triterpenes in Ganoderma lingzhi and its related species using high-performance liquid chromatography," Journal of Chromatography B, vol. 1068-1069, pp. 49-55, 2017.

[22] C. Chunru, Y. Min, Y. Kate et al., "Identification of metabolites of ganoderic acid D by ultra-performance liquid chromatography/quadrupole time-of-flight mass spectrometry," Drug Metabolism and Disposition: The Biological Fate of Chemicals, vol. 40, no. 12, pp. 2307-2314, 2012.

[23] W. Tang, T. Gu, and J.-J. Zhong, "Separation of targeted ganoderic acids from Ganoderma lucidum by reversed phase liquid chromatography with ultraviolet and mass spectrometry detections," Biochemical Engineering Journal, vol. 32, no. 3, pp. 205-210, 2006.

[24] D. Hongling, X. Guangping, and Z. Naxi, "Quantitative analysis of ganoderic acid C2, G, and A in sporophore and spore powder of Ganoderma by HPLC," Drugs \& Clinic, vol. 01, pp. 41-43, 2013.

[25] L. Duanping, C. Shuo, and W. Yong, "Determination of ganoderic acid $\mathrm{A}$ in ganoderma lucidum water extracts by HPLC,” Modern Chinese Medicine, vol. 06, pp. 496-499, 2013.

[26] Y. Liu, Y. Liu, F. Qiu, and X. Di, "Sensitive and selective liquid chromatography-tandem mass spectrometry method for the determination of five ganoderic acids in Ganoderma lucidum and its related species," Journal of Pharmaceutical and Biomedical Analysis, vol. 54, no. 4, pp. 717-721, 2011.

[27] L. L. G. X. Chao, "UHPLC-MS/MS determination of ganoderic acid $\mathrm{A}$ and ganoderic acid $\mathrm{B}$ in ganoderma lucidum black tea," Physical Testing and Chemical Analysis (Part B: Chemical Analysis), vol. 08, pp. 909-913, 2016.

[28] S. Seiichi, K. Toshitaka, S. Kuniyoshi et al., "Detection of ganoderic acid A in ganoderma lingzhi by an indirect competitive enzyme-linked immunosorbent assay," Planta Medica, vol. 82, no. 8, pp. 747-751, 2016.

[29] S. Sakamoto, N. Kikkawa, T. Kohno, K. Shimizu, H. Tanaka, and S. Morimoto, "Immunochromatographic strip assay for detection of bioactive Ganoderma triterpenoid, ganoderic acid A in Ganoderma lingzhi," Fitoterapia, vol. 114, pp. 51-55, 2016.

[30] G. Yusakul, P. Nuntawong, S. Sakamoto et al., "Bacterial expression of a single-chain variable fragment ( $\mathrm{scFv}$ ) antibody against ganoderic acid A: a cost-effective approach for quantitative analysis using the scFv-based enzyme-linked immunosorbent assay," Biological \& Pharmaceutical Bulletin, vol. 40, no. 10, pp. 1767-1774, 2017. 